\title{
KELAYAKAN VIDEO TUTORIAL PEMBUATAN DONAT JAHE SUBMATERI PERAN TUMBUHAN DI BIDANG EKONOMI
}

\author{
Apriani $^{1}$, Entin Daningsih ${ }^{2}$, Yokhebed $^{3}$ \\ ${ }^{1,2,3}$ Program Studi Pendidikan Biologi, FKIP Universitas Tanjungpura, \\ Jalan Prof. Dr. H. Hadari Nawawi, Pontianak - 78124 \\ 1email: apriani23@yahoo.com
}

\begin{abstract}
Abstrak
Penelitian bertujuan untuk mengetahui kelayakan video tutorial sebagai media pembelajaran untuk membantu kegiatan pembuatan donat jahe(Zingiber officinale var. officinale) pada submateri peran tumbuhan di bidang ekonomi. Penelitian menggunakan metode deskriptif kuantittatif. Instrumen validasi video tutorial oleh ahli media terdiri dari 8 aspek dan 15 kriteria, sedangkan validasi oleh ahli materi terdiri dari 3 aspek dan 10 kriteria. Kelayakan video tutorial pembuatan donat jahe divalidasi oleh 3 orang ahli materi dengan hasil validasi yaitu RTV Тк sebesar 3,92 dan 3 orang ahli media dengan hasil validasi yaitu $\mathrm{RTV}_{\text {TK }}$ sebesar 3,44 yang termasuk dalam kategori valid. Sehingga secara keseluruhan video tutorial pembuatan donat jahe layak untuk digunakan (LD) sebagai media untuk membantu pembelajaran dalam pembuatan donat jahe pada sub materi peran tumbuhan di bidang ekonomi.
\end{abstract}

Kata Kunci: kelayakan, video tutorial, donat jahe.

\begin{abstract}
This research aimed to determine the feasibility of video tutorials as a learning medium to assist the activities of making ginger donut (Zingiber officinale var officinale) in the sub-material roles of plants in the economic field. This research used descriptive quantitative method. Validation instrument video tutorial by media experts consists of 8 aspects and 15 criteria, while validation by material experts consists of 3 aspects and 10 criteria. The eligibility of a video tutorial on making a ginger (Zingiber officinale var officinale) donut was validated by 3 material experts with validation result of $R T V_{T K}$ was 3.92 and 3 media experts with validation result of $R T V_{T K}$ was 3.44 included in "valid" category. Overall, video tutorial making donut ginger was feasible to used $(L D)$ as a learning medium to consist of making ginger donut on sub-material of plant role in economic field.
\end{abstract}

Keywords: feasibility, video tutorial, ginger donut.

\section{PENDAHULUAN}

Media pembelajaran merupakan suatu alat yang digunakan untuk memperlancar kegiatan pembelajaran dan bertujuan agar siswa lebih memahami kegiatan pembelajaran yang dilaksanakan. Media pembelajaran merupakan hal yang penting untuk berlangsungnya suatu pembelajaran di kelas. Media merupakan wahana penyalur informasi belajar atau penyalur pesan. Secara lebih khusus, pengertian media dalam proses belajar mengajar cenderung diartikan 
sebagai alat-alat grafis, fotografis atau elektronis untuk menangkap, memproses, dan menyusun kembali informasi visual atau verbal (Arsyad, 2013; Djamarah dan Zain, 2010; Kustiono, 2010).

Salah satu bentuk media pembelajaran yaitu berupa video tutorial. Video tutorial merupakan salah satu jenis media audio-visual yang dapat menggambarkan suatu objek yang bergerak bersama-sama dengan suara yang sesuai. Video menyajikan informasi, memaparkan proses, menjelaskan konsep yang rumit, mengajarkan keterampilan, menyingkat atau memperpanjang waktu, dan mempengaruhi sikap (Al-Firdaus, 2010).

Video tutorial (training) digunakan untuk menjelaskan secara detail suatu proses tertentu, cara pengerjaan tugas tertentu, cara latihan, dan lain sebagainya guna memudahkan tugas para trainer/instruktur/guru/dosen/manajer. Dalam penelitian yang dilaksanakan, informasi ditampilkan dalam kombinasi berbagai bentuk (shooting video, grafis, animasi, narasi, dan teks) yang memungkinkan informasi terserap secara optimal oleh para siswa.

Video juga bisa dimanfaatkan untuk hampir semua topik, model-model pembelajaran, dan setiap ranah pengetahuan, sikap, dan keterampilan. Pada ranah pengetahuan, siswa dapat mengobservasi rekreasi dramatis dari kejadian sejarah masa lalu dan rekaman dari peristiwa terkini, karena unsur warna, suara, dan gerak mampu membuat karakter terasa lebih hidup. Dengan melihat video, setelah atau sebelum membaca, dapat memperkuat pemahaman siswa terhadap materi ajar. Pada ranah sikap, video dapat memperkuat siswa dalam merasakan unsur emosi dan penyikapan dari pembelajaran yang efektif. Pada ranah keterampilan, video memiliki keunggulan dalam memperlihatkan bagaimana sesuatu bekerja, video pembelajaran yang merekam kegiatan pembelajaran/gerak dapat memberikan kesempatan pada siswa untuk mengamati dan mengevaluasi kembali kegiatan tersebut (Anderson, 1987).

Berdasarkan uraian yang telah dijelaskan, maka ujuan dari penelitian adalah untuk mengetahui kelayakan video tutorial untuk praktikum pembuatan donat jahe (Zingiber officinale var.officinale) pada submateri Peran Tumbuhan di Bidang Ekonomi. 


\section{METODE}

Metode penelitian yang digunakan adalah deskriptif kuantitatif. Penelitian yang dilakukan berupa pembuatan video tutorial praktikum yang dilaksanakan melalui tiga tahap, yaitu tahap penyusunan video tutorial praktikum, perbaikan video tutorial praktikum, dan tahap validasi video tutorial praktikum. Alat yang digunakan dalam penelitian adalah laptop dengan program software Windows Movie Maker, Filmora, dan Corel Video Studio untuk mengedit video, program software Powtoon, dan kamera. Bahan yang digunakan dalam penyusunan video tutorial adalah video pembuatan donat jahe, gambar tumbuhan yang termasuk dalam kingdom plantae, dan gambar tumbuhan yang melimpah di Kalimantan Barat khususnya Pontianak yaitu jahe dan pengenalan penilaian uji organoleptik pada makanan.

Isi dari video tutorial tersebut adalah pengolahan tumbuhan lokal yakni jahe menjadi suatu produk yang digemari masyarakat berupa donat sehingga plantae memiliki manfaat di bidang ekonomi yang lebih bervariasi. Adapun hal-hal yang terdapat pada video tutorial tersebut yakni terdiri dari judul, tujuan, alat dan bahan, langkah kerja, dan hasil.

Pengeditan video tutorial menggunakan aplikasi software Windows Movie Maker, Filmora, dan Corel Video Studio. Sebelum video tutorial divalidasi, maka dilakukan uji kelayakan instrumen validasi media video tutorial. Uji kelayakan instrumen dilakukan oleh 6 orang validator, yaitu 3 orang dosen dan 3 orang guru dengan kategori layak digunakan (LD), layak digunakan dan diperbaiki (LDP) dan tidak layak digunakan (TLD). Video tutorial dapat digunakan jika validator (ahli materi dan ahli media) mengatakan semua kriteria pada lembar uji kelayakan instrumen disimpulkan layak digunakan.

Validasi video tutorial yang dilakukan menggunakan kriteria yang dimodifikasi dari Yamasari (2010), yaitu terdiri dari validasi materi dan validasi media. Lembar validasi ahli materi dan ahli media tersebut merupakan modifikasi dari Amrulloh, dkk. (2013). Adapun skala yang digunakan adalah skala likert dengan nilai 4 (Baik Sekali/BS), nilai 3 (Baik/B), nilai 2 (Kurang Baik/KB), dan nilai 1 (Tidak Baik/TB). Validasi video tutorial dilakukan oleh 3 orang ahli media 
dan 3 orang ahli materi. Ahli media terdiri dari 2 orang dosen dan satu orang guru. Sedangkan ahli materi terdiri dari 2 orang guru Biologi dan satu orang dosen Pendidikan Biologi FKIP Untan.

Setelah video tutorial selesai divalidasi oleh 6 validator dan dianalisis, maka diketahui kekurangan dari video tutorial tersebut. Selanjutnya dilakukan perbaikan untuk menghasilkan video tutorial yang baik sehingga bisa digunakan untuk media pembelajaran di sekolah.

\section{HASIL DAN PEMBAHASAN}

Media video tutorial yang dibuat digunakan untuk membantu siswa dalam melaksanakan praktikum pembuatan donat jahe. Pembuatan media video tutorial mengacu pada kompetensi dasar dan silabus kelas X SMA/MA yaitu kompetensi dasar 3.8. Video tutorial dibuat dengan menggunakan aplikasi editing seperti Windows Movie Maker, Corel Cideo Studio, dan Filmora. Video tutorial yang dibuat memiliki durasi selama 14 menit 45 detik. Isi dari video tutorial tersebut adalah pengolahan tumbuhan lokal yakni jahe gajah menjadi suatu produk yang digemari masyarakat berupa donat sehingga plantae memiliki manfaat di bidang ekonomi yang lebih bervariasi. Video tutorial terdiri dari pembuka, isi, dan penutup.
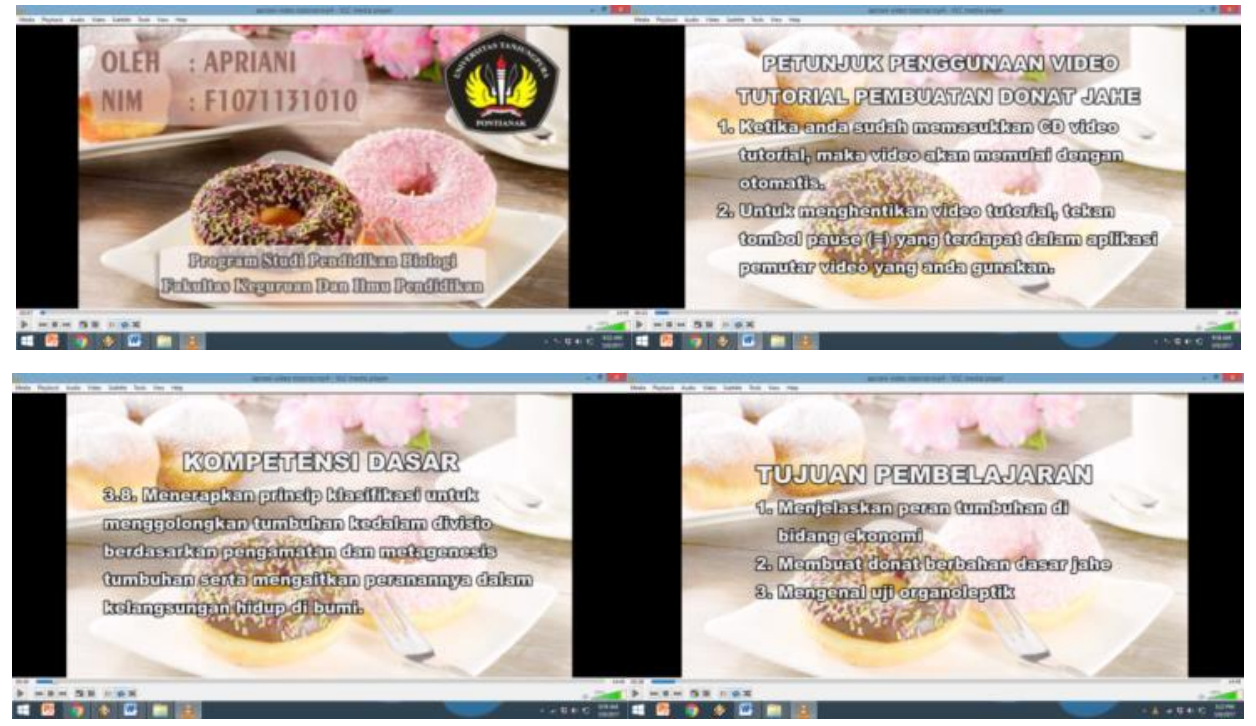

Gambar 1 Bagian Pembuka pada Video Tutorial 
Gambar 1 merupakan video tutorial yang berisi nama peneliti, judul video, dan logo Universitas Tanjungpura. Kemudian di bagian pembuka juga terdapat petunjuk penggunaan video tutorial, KD, dan tujuan pembelajaran. Setelah bagian pembuka, video tutorial juga terdiri dari bagian isi (Gambar 2).
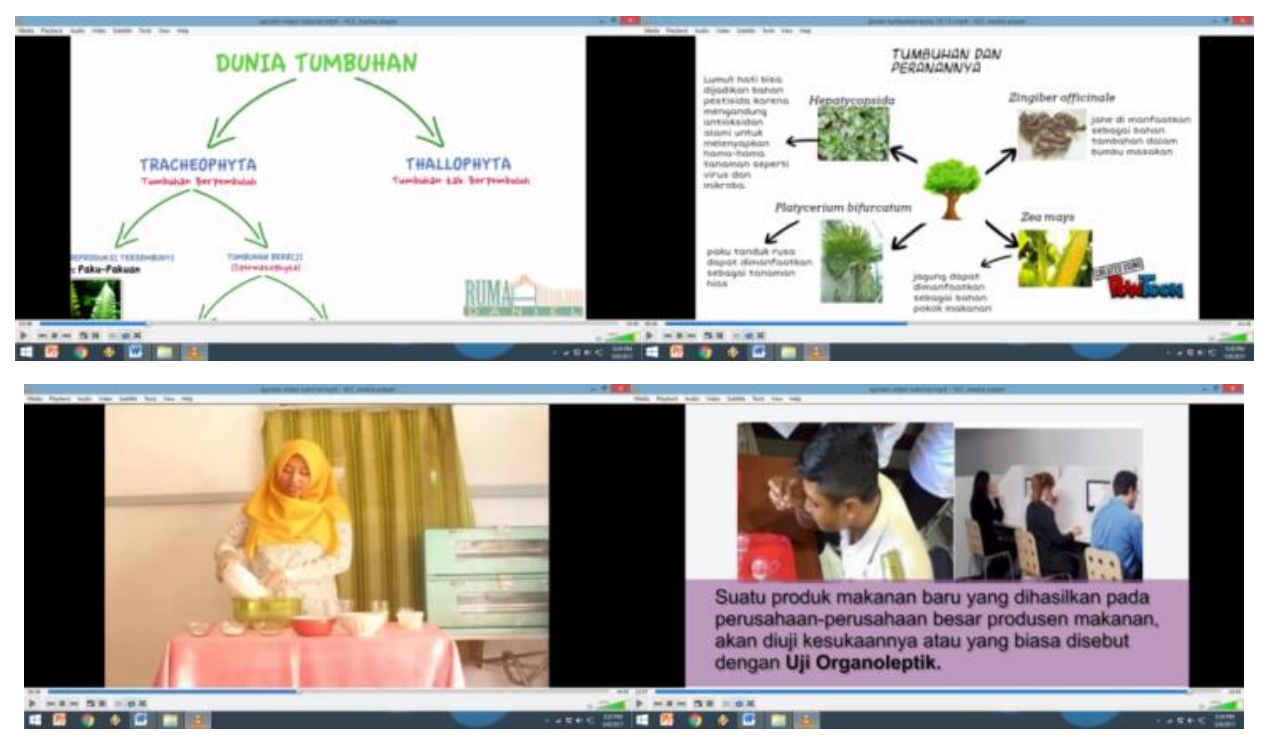

\section{Gambar 2 Bagian Isi Dari Video Tutorial}

Bagian isi video tutorial (Gambar 2) terdiri dari penjelasan singkat materi plantae, pengenalan tumbuhan yang mempunyai nilai ekonomi salah satunya jahe, produk-produk olahan jahe, tutorial pembuatan donat jahe, dan pengenalan uji organ oleptik. Sedangkan pada bagian penutup berisi ucapan terimakasih.

Hasil analisis lembar uji kelayakan instrumen validasi media video tutorial oleh 6 validator yaitu layak digunakan (LD). Setelah dilakukan uji kelayakan lembar instrumen validasi video tutorial, media video tutorial yang telah dibuat divalidasi oleh ahli media dan ahli materi untuk mengetahui kelayakannya sebagai media pembelajaran. Ahli media terdiri dari dua orang dosen Pendidikan Fisika dan satu orang guru mata pelajaran TIK. Data hasil analisis validasi video tutorial oleh ahli media dapat dilihat pada Tabel 1. 
Tabel 1 Data Hasil Analisis Validasi Video Tutorial oleh Ahli Media

\begin{tabular}{|c|c|c|c|}
\hline Aspek & Kriteria & $\mathrm{Ki}$ & $\mathrm{Ai}$ \\
\hline Kesederhanaan & $\begin{array}{l}\text { 1. Video tutorial yang dibuat memiliki } \\
\text { harga yang murah. } \\
\text { 2. Petunjuk penggunaan video tutorial } \\
\text { mudah dipahami. }\end{array}$ & $\begin{array}{l}3,33 \\
3,67\end{array}$ & 3,50 \\
\hline Audio & $\begin{array}{l}\text { 3. Ketepatan musik instrumen pada video } \\
\text { tutorial. } \\
\text { 4. Kejelasan antara musik instrumen dan } \\
\text { suara narator. } \\
\text { 5. Kejelasan suara narator dalam video } \\
\text { tutorial. }\end{array}$ & $\begin{array}{l}3,33 \\
3,67 \\
3,67\end{array}$ & 3,56 \\
\hline Keterpaduan & $\begin{array}{l}\text { 6. Kesesuaian urutan antar frame video } \\
\text { tutorial. }\end{array}$ & 3,67 & 3,67 \\
\hline Penekanan & $\begin{array}{l}\text { 7. Mengomunikasikan informasi dengan } \\
\text { akurat, jelas, dan efektif. }\end{array}$ & 3,33 & 3,33 \\
\hline Keseimbangan & $\begin{array}{l}\text { 8. Kesesuaian ukuran gambar dan tulisan } \\
\text { yang digunakan dalam video tutorial. } \\
\text { 9. Keseimbangan tata letak tulisan yang } \\
\text { digunakan dalam video tutorial. }\end{array}$ & 3,33 & 3,33 \\
\hline Bentuk & $\begin{array}{l}\text { 10. Daya tarik gambar yang digunakan } \\
\text { dalam video tutorial. } \\
\text { 11. Keterbacaan huruf yang digunakan } \\
\text { dalam video tutorial. }\end{array}$ & 3,33 & 3,16 \\
\hline Warna & $\begin{array}{l}\text { 12. Kesesuaian warna tiap frame dalam } \\
\text { video tutorial. } \\
\text { 13. Kefokusan gambar. }\end{array}$ & 3,67 & 3,50 \\
\hline Efektif & $\begin{array}{l}\text { 14. Ketahanan media. } \\
\text { 15. Penggunaan media untuk perorangan, } \\
\text { kelompok ataupun perkelas. }\end{array}$ & 3,33 & 3,50 \\
\hline$R T V_{T K}$ & & & ,44 \\
\hline
\end{tabular}

Hasil validasi yang diberikan validator pada aspek kesederhanaan kurang sempurna karena validator menilai biaya produksi untuk pembuatan video tutorial cukup mahal dan proses pembuatan membutuhkan waktu yang lama. Hal tersebut sesuai dengan pendapat Fatimah (2015) mengenai kekurangan media video yaitu untuk memproduksi video membutuhkan biaya yang tidak murah dan waktu yang tidak sebentar namun kelebihannya adalah video bisa disimpan dan bisa ditayangkan berkali-kali dalam satu kali kerja (produksi). Berdasarkan hasil 
validasi, tidak terdapat komentar dan saran dari ketiga validator ahli media untuk aspek kesederhanaan.

Aspek audio berkaitan dengan hal-hal yang mendukung pembuatan media video, meliputi narasi, sound effect, dan backsound musik. Pada aspek audio terdapat tiga kriteria (Tabel 1). Secara keseluruhan, ketiga kriteria tersebut dinyatakan valid, karena masing-masing kriteria secara berurutan memiliki nilai Ai sebesar 3,56 yang termasuk kedalam kategori valid. Menurut Arda dan Darsikin (2015), media pembelajaran yang dilengkapi dengan musik instrumental dapat menarik perhatian siswa. Hal tersebut diharapkan membuat siswa lebih bersemangat dan termotivasi.

Aspek keterpaduan mengacu pada hubungan yang terdapat diantara elemenelemen visual yang ketika diamati akan berfungsi secara bersama-sama dalam media pembelajaran dan elemen-elemen tersebut harus saling terkait dan menyatu. Pada aspek keterpaduan hanya terdapat satu kriteria (Tabel 1) dan dinyatakan valid karena memiliki nilai Ai sebesar 3,67. Urutan antar frame pada video tutorial haruslah sesuai antara satu frame dengan frame lainnya sehingga informasi yang disajikan dalam video tutorial dapat tersampaikan dengan sistematis. Hal tersebut sesuai dengan pendapat Hamalik (2010) yang menyatakan bahwa keruntutan merupakan hal terpenting dalam menyampaikan suatu cerita karena keruntutan bertujuan untuk memberikan gambaran yang sejelas-jelasnya kepada pembaca mengenai fase, urutan, langkah atau rangkaian terjadinya suatu hal.

Aspek penekanan terdapat satu kriteria (Tabel 1) dan memiliki nilai Ai sebesar 3,33 yang dinyatakan valid. Hal tersebut didukung dengan salah satu karakteristik atau kelebihan dari penggunaan media video menurut Munadi (2011) yaitu video mampu memperjelas hal-hal abstrak dan memberikan gambaran yang realistik. Walaupun aspek penekanan dinyatakan valid, namun hanya memiliki nilai Ai sebesar 3,33. Hal tersebut dikarenakan menurut validator video tutorial yang dibuat kurang dapat mengomunikasikan informasi dengan akurat, jelas, dan efektif. Sanaky (2009) menyatakan bahwa salah satu kelemahan dari video 
tutorial yaitu memiliki sifat komunikasi searah, sehingga tidak dapat memberi peluang untuk terjadinya umpan balik.

Aspek keseimbangan mencakup dua kriteria (Tabel 1). Aspek keseimbangan memiliki nilai Ai sebesar 3,33 yang termasuk kedalam kategori valid. Hal tersebut dikarenakan ukuran gambar dan tulisan yang digunakan sudah sesuai, serta tata letak tulisan sudah seimbang sehingga siswa tidak kesulitan membacanya. Ariani dan Haryanto (2010) menyatakan bahwa media audio visual yang baik yaitu harus memperhatikan adanya keseimbangan warna gambar dengan media, serta keseimbangan gaya teks dengan media.

Aspek bentuk mencakup dua kriteria (Tabel 1). Aspek bentuk memiliki nilai Ai sebesar 3,16 dan masuk kategori valid. Rendahnya nilai Ai pada aspek bentuk dikarenakan menurut validator bentuk huruf yang digunakan dalam video tutorial sedikit sulit terbaca, beberapa gambar yang digunakan juga kurang jelas terlihat. Menurut Ariani dan Haryanto (2010), dalam media pembelajaran peletakkan gambar dan teks harus sesuai agar menjadi komunikatif dan memudahkan pembaca menerima informasi yang disajikan. Hasil validasi yang diberikan oleh validator kurang sempurna karena validator menilai huruf yang digunakan kurang dapat terbaca dengan baik sehingga disarankan untuk mengganti bentuk huruf yang digunakan dalam video tutorial.

Aspek warna meliputi dua kriteria (Tabel 1). Secara keseluruhan aspek warna memiliki nilai Ai sebesar 3,50 yang juga dinyatakan valid. Berdasarkan hasil validasi yang dilakukan oleh validator, video tutorial telah memiliki warna yang sesuai pada tiap frame, serta memiliki kefokusan gambar yang cukup baik sehingga video tutorial tidak mengganggu penglihatan siswa ketika siswa menonton video tutorial pembuatan donat jahe. Menurut Kusrianto (2007), dalam desain visual pada umumnya, warna mewakili suasana kejiwaan pelukisnya dalam berkomunikasi. Warna juga merupakan unsur yang sangat tajam untuk menyentuh kepekaan penglihatan sehingga mampu menstimuli perasaan, perhatian, dan minat seseorang.

Aspek efektif meliputi dua kriteria (Tabel 1). Secara keseluruhan aspek efektif video tutorial memiliki nilai Ai sebesar 3,50 yang termasuk kategori valid. 
Hal tersebut dikarenakan media video tutorial merupakan media yang dapat disimpan dan digunakan dalam waktu yang sangat lama serta mudah digunakan karena cukup dengan laptop, televisi ataupun fasilitas yang terhubung dengan proyektor LCD video sudah dapat ditayangkan. Menurut Nugent (Sadiman, 2011), video merupakan media yang cocok untuk berbagai ilmu pembelajaran, seperti kelas, kelompok kecil, bahkan satu siswa seorang diri sekalipun. Dick dan Carey (Sadiman, 2011) menyatakan ada beberapa faktor yang harus dipertimbangkan dalam pemilihan media diantaranya yaitu faktor keluwesan, kepraktisan, dan ketahanan media yang digunakan. Hal tersebut diartikan bahwa media harus bisa digunakan kapan saja dan tidak sulit dioperasikan dengan peralatan yang ada di sekitarnya.

Berdasarkan hasil perhitungan validasi yang dilakukan oleh ahli media yang dapat dilihat padaTabel 1 , nilai $R T V_{T K}$ yang didapat yaitu 3,44. Mengacu pada Khabibah (Yamasari, 2010), jika nilai $3 \leq \mathrm{RTV}_{\mathrm{TK}} \leq 4$, maka media dikatakan valid. Pada hasil validasi yang didapat dari ahli media, media video tutorial dikatakan valid karena memiliki nilai $3 \leq \mathrm{RTV}_{\mathrm{TK}} \leq 4$ yaitu 3,44 .

Media video tutorial yang dibuat juga divalidasi oleh ahli materi yang terdiri dari dua orang guru mata pelajaran Biologi (MAN 1 Pontianak dan SMA Muhammadiyah 1 Pontianak) dan satu orang dosen Pendidikan Biologi. Adapun data hasil analisis validasi oleh ahli materi dapat dilihat pada tabel berikut.

Tabel 2 Data Hasil Analisis Validasi Video Tutorial oleh Ahli Materi

\begin{tabular}{|c|c|c|c|}
\hline Aspek & Kriteria & $\mathbf{K i}$ & $\mathbf{A i}$ \\
\hline Format & $\begin{array}{l}\text { 1. Kesederhanaan materi yang disajikan dalam } \\
\text { video tutorial }\end{array}$ & 4,00 & 4,00 \\
\hline \multirow[t]{4}{*}{ Isi } & $\begin{array}{l}\text { 2. Kesesuaian konsep video tutorial dengan } \\
\text { indikator pembelajaran }\end{array}$ & 3,67 & \\
\hline & 3. Kesesuaian materi dengan tujuan pembelajaran & 4,00 & \\
\hline & $\begin{array}{l}\text { 4. Kelengkapan informasi yang disajikan dalam } \\
\text { video tutorial }\end{array}$ & 4,00 & 3,92 \\
\hline & $\begin{array}{l}\text { 5. Kemudahan memahami materi yang disajikan } \\
\text { dalam video tutorial }\end{array}$ & 4,00 & \\
\hline
\end{tabular}




\begin{tabular}{lrlrr}
\hline Bahasa & 6. & Penggunaan bahasa yang mudah dipahami & 4,00 & \\
& 7. & Penggunaan bahasa yang sesuai dengan & 3,67 & 3,89 \\
& PUEBI (Pedoman Umum Ejaan Bahasa & & \\
& Indonesia & \\
8. & Bahasa yang digunakan sesuai dengan \\
& tingkatan sekolah & 4,00 \\
\hline
\end{tabular}

$R T V_{T K}$

3,92

Ahli materi menilai media pembelajaran berdasarkan aspek format, isi, dan Bahasa. Aspek format terdiri dari dua kriteria (Tabel 2).Secara keseluruhan aspek format memiliki nilai Ai sebesar 4 atau valid. Validator menilai bahwa materi yang ditampilkan singkat, padat, dan jelas dengan tampilan gambar dan tulisan yang sesuai materi sehingga tidak berlebihan. Materi yang disajikan sesuai dengan konsep pembelajaran, yaitu membahas peranan tumbuhan di bidang ekonomi.

Aspek isi terdiri dari lima kriteria (Tabel 2). Secara keseluruhan aspek isi dinyatakan valid karena memiliki nilai Ai sebesar 3,87. Menurut Warsita (2008), media video mempunyai potensi tinggi dalam penyampaian pesan maupun kemampuannya dalam menarik minat dan perhatian peserta didik. Arsyad (2013) menyatakan bahwa kriteria yang perlu diperhatikan dalam memilih media diantaranya sesuai dengan tujuan yang ingin dicapai dan tepat untuk mendukung isi pelajaran yang sifatnya fakta, konsep, prinsip atau generalisasi.

Aspek bahasa terdapat tiga kriteria (Tabel 2). Secara keseluruhan aspek bahasa pada video tutorial memiliki nilai Ai sebesar 3,89 yang masuk kategori valid. Hal tersebut dikarenakan video tutorial yang dibuat sudah menggunakan Bahasa Indonesia yang baik sesuai dengan aturan dan tidak menimbulkan penafsiran ganda.

Hasil analisis validasi oleh ahli materi dapat dilihat pada Tabel 2 yang nilai $R T V_{T K}$ didapat yaitu 3,92. Mengacu pada Khabibah (Yamasari, 2010), jika nilai 3 $\leq \mathrm{RTV}_{\mathrm{TK}} \leq 4$, maka media dikatakan valid. Sehingga validasi yang dilakukan oleh ahli materi dinyatakan valid, karena memiliki nilai $3 \leq \mathrm{RTV}_{\mathrm{TK}} \leq 4$ yaitu 3,92 . Video yang telah divalidasi kemudian dilakukan revisi sesuai dengan saran dari keenam validator, yang selanjutnya setelah dilakukan revisi video tutorial digunakan dalam kegiatan praktikum siswa membuat donat jahe. 
Media pembelajaran sangat bermanfaat bagi proses pembelajaran. Dengan menggunakan media pembelajaran, maka pembelajaran akan lebih menarik. Kustiono (2010) mengungkapkan bahwa dengan menggunakan video praktikum yang dilengkapi dengan pengenalan alat-alat dalam praktikum dan dilengkapi pula dengan simulasi praktikum, membawa peserta didik lebih mudah belajar tidak hanya di sekolah namun juga dapat dilaksanakan di rumah.

Setelah dilakukan validasi, selanjutnya video tutorial direvisi sesuai dengan saran-saran yang diberikan oleh keenam validator. Pada validasi ahli media secara keseluruhan revisi yang dilakukan sesuai dengan saran yaitu mengganti jenis tulisan yang sulit untuk dibaca dan warna tulisan disesuaikan dengan warna background sehingga tulisan dapat terbaca dengan jelas. Sedangkan untuk revisi dari ahli materi, saran yang diberikan yaitu mengganti animasi bola dunia dengan gambar pohon sehingga antara materi dengan icon yang digunakan dalam video tutorial lebih sesuai. Setelah media dilakukan revisi sesuai dengan saran-saran dari validator, kemudian video tutorial dapat digunakan dalam kegiatan praktikum di sekolah.

\section{SIMPULAN}

Berdasarkan hasil penelitian yang dilakukan, dapat disimpulkan bahwa video tutorial yang dibuat setelah diuji kelayakannya oleh 3 orang ahli media dan 3 orang ahli materi dinyatakan valid dan layak untuk digunakan dalam membantu proses kegiatan praktikum pembuatan donat jahe yang dilakukan oleh siswa. Hasil validasi oleh ahli media yaitu RTV $_{\mathrm{TK}}$ sebesar 3,44 yang termasuk dalam kategori valid, sedangkan ahli materi dengan nilai $\mathrm{RTV}_{\mathrm{TK}}$ sebesar 3,92 yang termasuk dalam kategori valid atau layak digunakan.

\section{DAFTAR PUSTAKA}

Al-Firdaus, I. 2010. Buku Lengkap Tuntunan Menjadi Kameraman Profesional. Yogyakarta: Buku Biru.

Amrulloh, R., Yuliani, \& Isnawati. 2013. Kelayakan Teoritis Media Pembelajaran Multimedia Interaktif Materi Mutasi Untuk SMA. Bioedu, 2(2). 
Anderson, K. 1987. Kerangka Landasan untuk Pembelajaran, Pengajaran, dan Asesmen Revisi Taksonomi Pendidikan Blom (Terjemahan). Jakarta: Pustaka Pelajar.

Arda, S. S. \& Darsikin. 2015. Pengembangan Media Pembelajaran Interaktif Berbasis Komputer untuk Siswa SMP kelas VII. Mitra Sains, 3(1).

Ariani, N. \& Haryanto, D. 2010. Pembelajaran Multimedia di Sekolah. Jakarta: Prestasi Pustakaraya.

Arsyad, A. 2013. Media Pembelajaran. Jakarta: Raja Grafindo Persada.

Djamarah, S. B, \& Zain, A. 2010. Strategi Belajar Mengajar. Jakarta: Rineka Cipta.

Fatimah, N. 2015. Produksi Film Dokumenter Religi "Bukan Seperti Miskin Tidak Seperti Kaya". Skripsi. (Online, tersedia di http://eprints.walisongo.ac.id/5276/1/101211027.pdf, diakses Tanggal 27 Mei 2017).

Hamalik, O. 2010. Proses Belajar dan Mengajar. Jakarta: Bumi Aksara.

Kusrianto, A. 2007. Pengantar Desain Komunikasi Visual. Yogyakarta: Andi Offset.

Kustiono. 2010. Media Pembelajaran: Konsep, Nilai Edukatif, Klasifiasi, Praktek Pemanfaatan dan Pengembangan. Semarang: Unnes Press.

Munadi, Y. 2011. Media Pembelajaran. Jakarta: GP Press.

Sadiman, A. S. 2011. Media Pendidikan, Pengertian, Pengembangan, dan Pemanfaatannya. Jakarta: Raja Grafindo Persada.

Sanaky, A. H. H. 2009. Media Pembelajaran.Yogyakarta: Safiria Insania Press.

Warsita, B. 2008. Teknologi Pembelajaran: Landasan \& Aplikasinya. Jakarta: Rineka Cipta.

Yamasari. 2010. Pengembangan Media Pembelajaran Matematika Berbasis ICT yang Berkualiatas. Seminar Nasional Pasca Sarjana. ISBN No. 979-5450270-1. 